DOI: $10.1515 / \mathrm{rpp}-2016-0012$

\author{
Doctor of Pedagogical Science, Associate Professor, NATALIA PAZYURA \\ National Aviation University, Ukraine \\ Address: 1 Kosmonavta Komarova Ave, Kyiv, 03058, Ukraine \\ E-mail: npazyura@ukr.net
}

\title{
INFLUENCE OF SOCIOCULTURAL CONTEXT ON LANGUAGE LEARNING IN FOREIGN COUNTRIES
}

\begin{abstract}
Professional foreign language training is offered to cultivate the ability to master cross-cultural communication in the sphere of future professional activity. By means of intercultural competence of foreign language we are raising professional competence, too. In countries where English is the native language, it is taught to speakers of other languages as an additional language to enable them to participate in all spheres of life of that country. In many countries where it is an official language and language of instruction, as most communication outside school is in the local languages it is taught as language to learn other disciplines. These are two contrasting contexts for enhancing the English language skills. In both settings there are concerns about students' difficulties in developing adequate English proficiency to successfully learn content through that language. This paper analyzes the influence of sociocultural factors on the students' motivation to learn English in different countries, reveals main problems and difficulties in oral English teaching practice, illustrates the relationship between oral English teaching and cross-cultural communication competence. On the one hand, cross-cultural communication plays an essential role in oral English teaching; besides, oral English teaching promotes cross-cultural communication competence. On the other hand, in some countries English is not the prerequisite of future successful career. But anyway the author insists on consistency of English teaching concept with that of the world. Improving the students' cross-cultural oral communication ability is impossible without laying equal stress on cross-cultural communication competence and oral English teaching.

Key words: cross-cultural communication, culture, English teaching, motivation, traditions, sociocultural factor.
\end{abstract}

\section{INTRODUCTION}

At the present stage of Ukraine's development it is critical to develop intercultural relations with the European States for close cooperation in economic and political spheres. Therefore, a necessary quality of a modern specialist is the ability for professional communication in a foreign language, which cannot be done effectively without knowledge of rules and norms of cross-cultural communication. In this context we should turn our attention to the experience of other countries in the world in which English is not a national language and is taught as foreign in educational establishments. On the other hand, we should not underestimate the influence of sociocultural aspects on the process of acquisition of foreign language skills. That is why the question of national culture as motivating factor is of certain interest to us.

Foreign language training is offered to cultivate the ability of cross-cultural communication in the sphere of future professional activity. That is why a foreign language 
learning in higher education institutions should be carried out with cultural peculiarities, because a future specialist of a new type, who masters a foreign language, often has to work at the international level, to adapt themselves to the new means of communication, to learn another culture and to contemplate on their own ethno-cultural sources, quickly adjusting to a multicultural environment and showing a tolerant attitude toward foreign language and culture.

\section{THE AIM OF THE STUDY}

The purpose of this article is to study the influence of cross-cultural factors on the process of foreign language training of students in different countries where English is taught as a second foreign language, revealing the influence of cultural aspects on the motivation of student learning and peculiarities of communicative competence formation in foreign countries.

\section{THEORETICAL FRAMEWORK AND RESEARCH METHODS}

The problems associated with the process of learning a foreign language, has always attracted close attention of domestic and foreign scientists and teachers, who stressed the importance of competence: G. Ball, V. Baydenko, I. Bekh, G. Belitskaya, L. Berestova, N. Chomsky, G. Degtyareva, N. Grishanova, S. Goncharenko, A. Kochubey, V. Kremen, V. Kunitsyna, N. Kuzmina, A. Markova, J. Raven, I. Voynar, G. White etc. Significant contribution to the study of the process of learning foreign languages was carried out in philological direction by A. Leontovich, S. Ter-Minasova, N. Troshina, in ethno-psychology by V. Krysko, N. Lebedeva, V. Sadohin, A. Stefanenko. However, to ensure the effectiveness of the process of forming foreign language competence with sociocultural peculiarities of the process it will be useful to appeal to the experience of other countries on this issue which has remained understudied yet.

For our research we used scientific general methods which are main ways of studying scientific sources and comparative-historical method for synchronic comparison of events in the different regions.

\section{RESULTS}

In many countries of the world unprecedented educational reforms take place aimed at improving the efficiency of language learning and especially English as the international language, without the knowledge of which a specialist is not considered competitive in the labour markets. In recent years Ministries of education have been actively presenting the National bilingual program to provide citizens with the opportunity to learn two foreign languages (English and native) and thus to strengthen the position of countries in world politics and transnational markets (Abad, 2013).

Today more and more people are realizing the importance of English in professional and everyday life. The English language is the dominant language of the world, which is native for the population in five countries (Australia, Canada, the UK, New Zealand, the USA), which B. Kachru refers to as so-called "inner circle". English is the official language in many other countries, in former colonies of Great Britain, which are defined as "the outer circle". According to D. Crystal since English is used in countries of the outer circle, together with native languages, its role differs from the role in countries of "the inner circle" as each country has its own standards of communication.

In most countries of the outer circle foreign language training takes place in polycultural conditions, which is why students use English for specific purposes, mostly, in formal education, because outside the classroom the bulk of communication occurs in the native language (Roy-Campbell, 2014). In countries where English is native, it is taught for non-English speaking immigrant students as additional to ensure that they had the opportunity to participate in all spheres of life in English-speaking countries. Thus, we can 
state the existence of two contrasting contexts for learning English: English-speaking students' learning to improve general education knowledge and skills and training of nonEnglish speaking students for their further socialization in an English speaking environment. Common to both these contexts, although contrasting, it is the problem of improving the efficiency of mastering the English language for successful study of the content of other disciplines, particularly at the secondary school level (Roy-Campbell, 2014).

It is noted in the analyzed literature that communicative competence is the overall "design", which covers all the necessary skills for effective communication using verbal and nonverbal means. L. Bachman and A. Palmer believe that it is distributed at the organizational and pragmatic knowledge. Organizational knowledge is the knowledge of grammar at the level of words and sentences, textual knowledge, which provides students with the ability to communicate and interpret the words of the interlocutor and sociolinguistic knowledge, which enables language users to communicate effectively in the sociocultural context. In addition to these types language communicative competence includes strategic competence and psychomotor skills (Abad, 2013).

We are sure that in the context of teaching non-English speaking students it is important to highlight the values of culture and tradition of their country, which greatly affect the students' motivation to learn a foreign language. Language and culture are interrelated components, which cannot be considered separately (Sun, 2015). As culture cannot be separated from language, and language permeates all aspects of life of the people, with which they build, understand the world and convey knowledge from generation to generation. The language forms a specific people as a cultural group, separating it from others (Yesid, Almeciga, 2010).

A well-known knowledge is that language is one of the main factors for the functioning of a society. In society it performs a variety of functions: nominative (the ability of language to denote and to represent things and processes), cognitive (participation in the learning process), communication (participation in the process of communication between people), etc.

Language allows people to identify themselves as members of a particular social group, which has its own vision of the world. It allows people to recognize their potential in the present time and to see the prospects of development in the future based on past experience. P. Freire and D. Macedo believe that these components are closely connected with economic interests and ideology of the nation which is directed to the promotion of the poor, unprivileged citizens and national minorities into the logic of national unity, the dominant cultural tradition. D. Hymes believes that the emergence and functioning of a language is directly associated with national traditions (Yesid, Almeciga, 2010).

We should emphasize that traditions and sociocultural context has a significant impact on students' attitudes to learning English throughout the world. If the sociocultural environment contributes to the development of competition, it creates a positive attitude to learning and forms the motivation to learn English. A positive attitude and motivation towards learning English are often conditioned by the social environment. Interesting fact is that this phenomenon exists in all countries of the world, and theoretical studies indicate that competitive and conducive environment greatly increases motivation for learning.

In addition, different researches show that English proficiency is significantly affected by diversified national and sociocultural factors. For instance, in Saudi Arabia the Arabic language is considered a linguistic, cultural and religious heritage of the society. At the same time, the English language is not considered by the majority of the population the 
only means for a successful life, although the lack of English language skills in communication is one of the major obstacles to admission to higher education institutions in the country. Moreover, it should be noted that there is no motivation to learn the English language in families if the parents are also indifferent to it. Some religious leaders have expressed fears that, if the English language is extended in the country, their own linguistic, cultural and religious rules of morality will be forgotten. Although, it should be underlined that the government of Saudi Arabia spends significant funds to education and raising educational standards in training the English language in accordance with international requirements (Ahmad, 2015).

We believe it to be necessary to consider national views regarding foreign language training and sociocultural factors that affect the process of mastering foreign language competence in some Asian, Latin American countries and Middle East countries in more details. For this we turn to the definitions of the main concepts of the study. According to the Oxford dictionary, a tradition is a longterm custom or belief that is passed from one generation to another, and that affects all aspects of human life, including the attitude to such values as training and education (Ahmad, 2015). The concept of tradition is often considered a major component of religious beliefs, culture, knowledge and skills that do not end with the death of a generation, but are deliberately preserved and passed on each generation following. This provides the link between generations and the preservation of national values, norms, symbols, attitude and behaviour throughout the history of the mankind. Tradition, therefore, is the principle of unity, identity in any culture.

It is important to recall that there is a very strong devotion to traditions in Saudi Arabia, and this saves the country from the obsession for the English language and its mass learning. Therefore, in such circumstances, the English language has never been recognized as an important factor of a successful life in this society. At the same time, in other countries there is a perception that the English language is an important factor for obtaining a higher social status, respect etc (Ahmad, 2015).

If we consider the situation in Saudi Arabia it is worth mentioning that scientists have noted a significant difference between the curricula at schools and universities. At universities there is the sufficient number of qualified English language teachers, introduced advanced training and the latest educational technology with the use of information and communication equipment (Ahmad, 2015). In a Latin American country like Colombia, foreign language training for national minorities focuses on education of the awareness of students' national identity, their understanding of the world, their relationship with the bigger nations (Yesid, Almeciga, 2010). However, we should pay attention to the fact that there is a lot of lands and enterprises owned by foreign companies in Colombia and therefore foreign language training should include some sociopolitical issues to facilitate the realization of individual and collective identity (Yesid, Almeciga, 2010).

In China as one of the Asian countries with the fastest growing economy the Ministry of Education notes that the teaching of English at colleges should be focused on acquiring skills of cross-cultural communication, the development of the common knowledge of a foreign language, especially listening and speaking skills required for real life situations. Implementation of effective communication is considered extremely important for future career and life in a multicultural society (Sun, 2015).

It is noted in the curriculum in the English language at Chinese schools that the main aim of training is to improve students' abilities to listen, speak, read and translate. However, if students do not have the ability to communicate in real conditions, the language learning is useless. In non-English speaking countries the situation is complicated 
by the fact that many teachers have a strong accent, which, and as they say, they do not realize. Moreover, the teachers themselves must continually improve and set an example for the students in the correct pronunciation. Chinese teachers noted that often while learning a foreign language, students are afraid to make a mistake, and this is a barrier for those who do not have good linguistic environment. Regardless of language proficiency, the main objective usually is a study of the speech patterns at oral lessons at Chinese schools, and therefore, after lessons a student still focuses his/her attention on reading and writing. Therefore, an important task is to change the methods of teaching oral speech (Sun, 2015).

$\mathrm{S}$. Krashen notes that the main function of the teacher in a classroom is to provide students with the opportunity to obtain necessary knowledge, and thus the classroom becomes a place for obtaining such knowledge, to which they have never had access to under other circumstances. At the same time teachers should offer students the opportunity to practice the language in situations in which any person may find themselves in everyday life and learn how to solve cultural conflicts. Therefore, the oral lessons turn into a place where students have the opportunity to improve their verbal and non-verbal communication skills, and the acquisition of cross-cultural communication skills is the main part of this process. Thus, the ultimate goal of language training is to teach students to communicate freely with others and to improve the common cultural knowledge and skills (Sun, 2015).

As the organizer of oral speech, the teacher should provide a good example for students. Only with the help of certain knowledge in intercultural communication, the teacher can control the class with the highest mastery. To do this teachers need to have a better linguistic basis and intercultural competence. As a result of the literature analysis we can conclude that the lack of understanding the culture of the nation, the language studied by the students is the main cause of failures during the acquisition of skills and cross-cultural communication. In most cases, the focus is made on traditional aspects of learning (pronunciation, grammar, vocabulary). Unfortunately, the study of the respective cultures that are behind the language are often ignored. It results in that students have no idea about the culture and values of English-speaking countries. This is often the cause of errors and lack of understanding between them and English-speaking interlocutors. Another reason for the poor state of the proficiency in foreign language communication is the lack of the English speaking environment. This occurs when the classroom teacher plays a major role, and students remain passive learners who only memorize speech patterns. As a result, such practice is not able to ensure communication effectiveness because students' participation is limited and passive. Although students remember the set expressions and idioms, they make a lot of mistakes, because they do not understand their inherent values that are determined by culture.

In addition, students lack opportunities to use what they learn in class in a real situation. Another reason for the unsatisfactory English proficiency is misunderstanding the style, the choice of which depends on the specific situation in which it is important and the content of the conversation, the origin of interlocutors and the type of communication. Often students do not pay attention to the rank of the interlocutor, the environment in which the conversation occurs, which, in its turn, leads to the wrong intercultural communication.

In the analyzed materials the researchers note that for improvement of students' cross-cultural competence oral speech teaching should be based on relevant pedagogical, psychological and linguistic theories. Oral speech teaching assumes differently directed interaction according to the learning objectives, content, strategies and assessment methods. Foreign scientists determined orientation to the student, a real linguistic environment, 
interaction with teachers as the main factors of effective foreign language training and improvement of intercultural communication skills of the student (Sun, 2015).

Another important aspect of foreign language training as an organized activity is a choice of topics in the curriculum. In this context, the efficiency of the educational process depends on the direct connection to the purpose with which the language is being studied. In the context of schooling teaching depends on the curriculum standards and curriculum approved by the educational authorities of the country (Roy-Campbell, 2014). But the analyzed literature indicates that in a college foreign language training should take into account polycultural nature of a society, with the addition of subjects of cultural character (Sun, 2015). It is useful for the development of intercultural competence to invite well-known scholars and experts to conduct lectures on intercultural issues, send teachers abroad and engage extracurricular activities for the education for understanding intercultural communication, awakening cultural consciousness. This may be cultural forums, discussions of foreign films, English language competitions, debates etc.

\section{CONCLUSIONS}

Thus, the analysis allows us to draw a conclusion about the importance of language learning not only as a "coded system of signs". One of the necessary conditions for effective foreign language training is to create conditions for students to master the specifics of cross-cultural relations, namely, differences in the structures of speech acts of native and studied languages, the system of values of the target culture, peculiarities of verbal and non-verbal behaviour in accordance with the norms of national culture. We should bear in mind that in some countries the English language has never been recognized as an important factor for a successful life in this society. And this factor must be taken into consideration while working out curriculum and content of education for these particular countries.

Further research is planned to direct on studying the issues of teaching special subjects in specialized education institutions by means of English in foreign countries.

\section{REFERENCES}

1. Abad, J. (2013). Pedagogical Factors that Influence EFL Teaching: Some Considerations for Teachers' Professional Development. Profile, Colombia, Volume 15, No 1, pp. 97-108

2. Ahmad, J. (2015). Traditional and Sociocultural Barriers to EFL learning: a Case Study. English Language Teaching, Volume 8, No 12, pp. 191-208.

3. Roy-Campbell, Z. (2014). Teaching English as a Second Language in Kenia and the United States: Convergences and Divergences. Global Education Review, No 2 (2), pp. 84-97.

4. Sun, Ch. (2015). The Cultivation of Cross-cultural Communication Competence in Oral English Teaching Practice. English Language Teaching, Volume 8, No 12, pp. 7-9.

5. Yesid, W., Almeciga, E. (2010). Silenced Fighters: Identity, Language and Thought of the Nasa People in Bilingual Contexts of Colombia. Profile, Colombia, Volume 12, No 2, pp. 125-140. 